\title{
Weight and Price Optimization of Truss Construction with Using Genetic Algo- rithm
}

\section{Lukáš Zeizinger, Martin Jonák}

Faculty of Mechanical Engineering, Brno University of technology. Technická 2896/2, 61669 Brno. Czech Republic. E-mail: lukas.zeizinger@vutbr.cz, jonak@fme.vutbr.cz

This article deals with optimization of the truss structure. A genetic algorithm is used for this optimization. Within the strength calculation of the truss structure a normative assessment of the beam and their buckling stability is implemented. Also, the entire calculation is designed to use only standard profiles. In the first task, the optimization is focused on the weight of the structure, and in the second, on its price. There are also developments using different population sizes for individual cases, which will be described below. At the end of the work, a hypothesis is made for the link between price optimization and weight reduction.

Keywords: truss construction, genetic algorithm, weight optimization, price optimization.

\section{Introduction}

The structure optimization is long-standing problem that is decoded for many years. For engineers, this problem is linked to material development and stiffness analysing. Currently, the most widespread optimization procedure is the use of mathematical optimization to find a minimal solution [17]. For example, this is widely used in the automotive industry to optimize the machine's carrier frame, which must transfer loads from payload, differential, wheels and more $[7,8,9,14]$. The stiffness analysis brings the possibility of indicating which beams are oversize and engineering optimization suggest better solutions. It is a way to find a better solution that should have similar or better mechanical properties [4].

This paper is focused on the optimization of the truss structure using genetic algorithm. In many cases, weight and price are very important aspects for the design of a steel structure. It outlines the inclusion of the price and weight of the steel truss structure in the overall calculation chain. Therefore, for a thorough understanding of the optimization issue, these criteria were chosen separately. In this case, the optimization criterion will be weight or cost.

The genetic algorithm was chosen for the optimization because it is a very up-to-date method that experiences a great expansion in engineering applications [11]. In most scientific articles published on the topic of truss structure optimization the buckling stability of members is neglected [10]. Without calculation the buckling stability of beams, it is not possible to design a truss structure for real application, of course, brings a logical follow-up to the profiles used, which are selected only from standardised. As an example of engineering application, the optimization was performed on 3D truss construction with 25 beams.

\section{Algorithm}

Since the 1970s, the deformation variation finite element method (FEM) has been a widely accepted method, gaining popularity on the rise of $\mathrm{PC}$ computational possibilities. Nowadays, this method is the dominant solution to truss structures. FEM is based on the Lagrange Variation Principle and premises of linear mechanics. This case was defined using a system of algebraic equations, these equations are adjusted to the following matrix form, see equation 1 [15],

$$
k_{g} \cdot \delta_{g}=T^{T} \cdot k \cdot \delta=F,
$$

where:

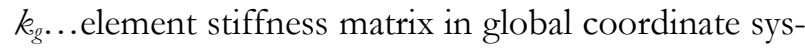
tem $\left[\mathrm{N} \cdot \mathrm{mm}^{-1}\right]$,

$\delta_{g} . .$. matrix of deformation parameters in global coordinate system $[\mathrm{mm}]$,

$T^{T} \ldots$ transposed transformation matrix [-],

$k$...element stiffness matrix in local coordinate system $\left[\mathrm{N} \cdot \mathrm{mm}^{-1}\right]$,

$\delta . .$. matrix of deformation parameters in local coordinate system $[\mathrm{mm}]$,

F...matrix of external force $[\mathrm{N}]$.

\section{Genetic algorithm}

The genetic algorithm (also referred to as "GA") is an optimization method, which belongs among population-based meta-heuristic optimization methods, along with simulated annealing, swarm optimization etc. These methods work with multiple solutions at the same time. The GA is based on some principals of the evolutional biology and was firstly introduced by 
J. H. Holland in [5]. This method is useful for solving tasks where the exact solution does not exist or it is hard to find it. Nowadays, the GA is often used in a wide spectrum of optimizations tasks and engineering applications. The main advantages are the simplicity of its implementation, algorithm autonomy and high probability to obtain a solution lying near the global extrema [13].

GA works with population of candidate solutions, and each member of this population, often called individual or chromosome, consists of genes in which optimized parameters are encoded. There are exist multiple ways how to encode these parameters into genes - binary, integer, real, etc. Choosing of the right encoding depends on the type of a solving task [16].

In a typical implementation of a GA (a generation model), the first generation is composed of randomly generated individuals. Next, in the transition to the new generation, the fitness function is evaluated for each individual. The functional value of the fitness function expresses the quality of the solution represented by the individual. All individuals are sorted according to their fitness value and next by applying genetic operators (selection, crossover and mutation) the new population (offspring) is created. The process is repeated and the quality of solutions in the population increase. The algorithm usually stops when a sufficient quality of one or more solutions is achieved or after a predetermined number of iterations (generations). It should be noted that in a GA a stochasticity plays an important role.

In order to optimize the truss construction presented in this article, a generation model of GA was chosen. The optimized parameters were beam types (shape and size) and they were chosen from the Table 2. Although the values to describe beam types could be only in the form of integer (corresponds to table rows), these values had been normalized to an interval $<0 ; 1>$ and when the fitness function was calculating, values were denormalized. The fitness function was the strength calculation of the truss structure including the buckling and optimization criterium was weight of the structure and next price of the structure. For both criteria, the goal of the optimization was minimization.

The following is a description of the genetic operators. For selection, individuals were chosen by using tournament selection [3] in which two individuals were randomly chosen from population and one with better fitness remains. This process was repeated until the "group of winners" had same size as population. Next, offspring generation was created from this group. This process is called crossover, and during crossover a new individual - offspring is created from genes of two selected individuals - parents. In this case, the one-point crossover [6] was used. Finally, a mutation operator was applied to a randomly selected gene of a randomly selected individual with relatively low probability, which inversely depends on number of genes [12]. The main purpose of this operator is to change some offspring in such way, that they do not contain any exact combination of genetic information from their parents. Due to the mutation, individuals do not stagnate and can escape from local extremes.

Elitism was used to preserve the best individuals [1]. The elitism is a process in which a certain number of individuals are moved directly to the next population, so they are not lost during application genetic operators.

See Table 3 below for more details.

\section{Conditions}

The project - optimization algorithm including computational model of a truss structure - was prepared in the programming language Python version 3.7. It was calculated on a computer with a 64-bit operating system, 32 GB RAM and AMD Ryzen 7 2700X $3.70 \mathrm{GHz}$ processor. All times listed below are converted to single-threaded task.

As described in the previous chapter, the initial initialization of individuals is required to trigger a genetic algorithm. The number of individuals in the population is the one of the attributes that changes the size of the searched space. The number of individuals was selected at 250, 2500 and 25000. Furthermore, the limitation criteria, namely the number of generations per 100 or if the value of the fitness function has not changed for 30 generations, were also chosen in which GA should be terminated. The initialization split is uniform distribution at the interval $\langle\alpha, \beta\rangle$. Therefore, its probability density of function $f(x)$ is given by equation 2, where

$$
f(x)=\frac{1}{\beta-\alpha} \text { for } \alpha \leq x \leq \beta .
$$

An interval of $<0 ; 1>$ was selected for this project [2].

One-dimensional optimization with weight minimization was chosen as the first example. A truss structure that will have a minimum mass regardless of production costs is wanted. The second example was chosen as cost minimization. A truss structure is being sought, which will have a minimum cost regardless of weight.

\section{Engineering applications}

The 25-bars reference truss construction was selected as seen in the Fig 1. Points A, B, C and D are fixed and there are limited displacements and rotations of these joints at these points. Members that cross each other but have not defined a joint in their contact do not affect each other. In point I and J, $50 \mathrm{kN}$ forces are applied in the negative direction of the $\mathrm{Z}$ axis as seen in Fig 2. Furthermore, the applied gravity in the 
form of force acting on each beams is adequate to its weight.

The calculation of this structure is considered as a truss with all beams assumptions and joints. The points are connected by trusses and the coordinates of the points can be found in Table 1. For calculation of buckling stability was used European standard; EN 1993-1-1 (2005): Eurocode 3: Design of steel structures - Part 1-1: General rules and rules for buildings. Standardized profiles according to standards were also used, see attached Table 2.

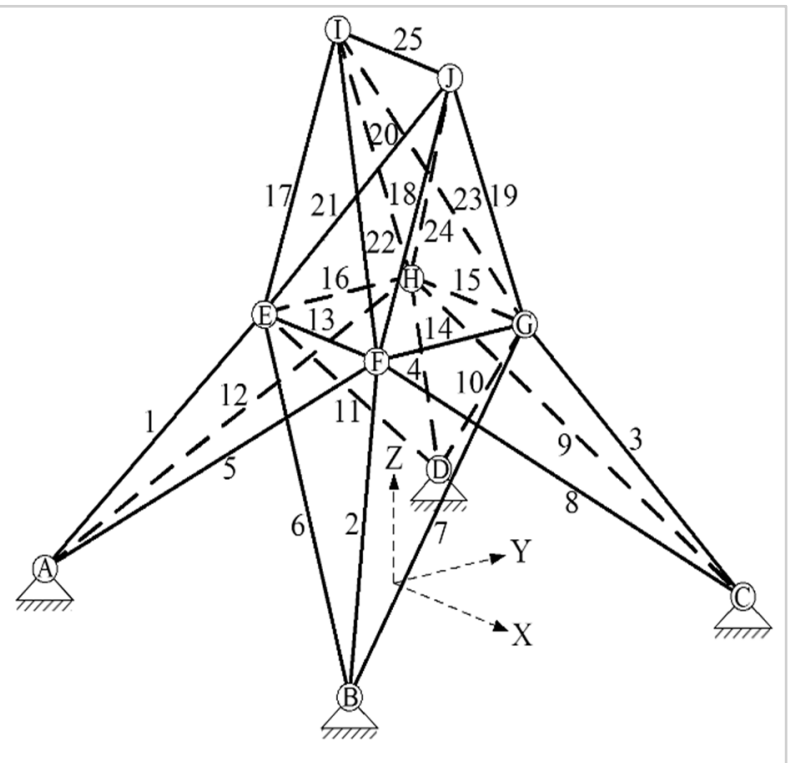

Fig 1 Truss construction design of members and links in global coordinate system.

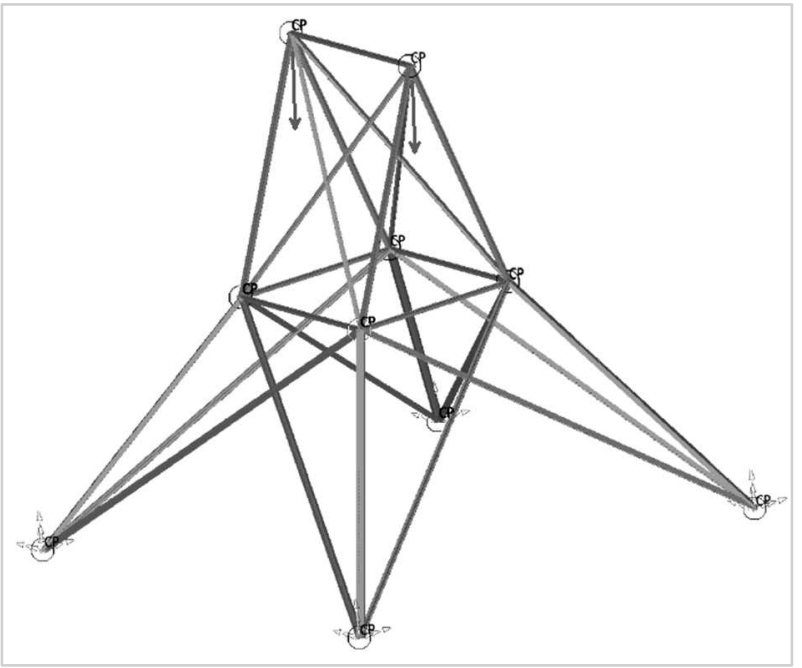

Fig 2 FEM model of truss construction with load and boundary conditions in NX.

Tab. 1 Table of points in global coordinate system.

\begin{tabular}{|c|c|c|c|}
\hline Point name & $\mathrm{X}[\mathrm{mm}]$ & $\mathrm{Y}[\mathrm{mm}]$ & $\mathrm{Z}[\mathrm{mm}]$ \\
\hline A & -2540 & -2540 & 0 \\
\hline B & 2540 & -2540 & 0 \\
\hline C & 2540 & 2540 & 0 \\
\hline D & -2540 & 2540 & 0 \\
\hline E & -952 & -952 & 2540 \\
\hline F & 952 & -952 & 2540 \\
\hline G & 952 & 952 & 2540 \\
\hline H & -952 & 952 & 2540 \\
\hline I & -952 & 0 & 5080 \\
\hline J & 952 & 0 & 5080 \\
\hline
\end{tabular}

Tab. 2 Table of standardized profiles.

\begin{tabular}{|l|l|l|l|}
\hline Standard & Profile & Dimension [mm] & $\begin{array}{l}\text { Minimum order } \\
\text { length [mm] }\end{array}$ \\
\hline DIN 1025-1 & Hot rolled I-sections, I - series & $80,100,120,140,160$ & 6000 \\
\hline DIN 1025-5 & Hot rolled I-beams, IPE - series & $80,100,120,140,160$ & 6000 \\
\hline DIN 1026-1 & Hot rolled U-beam, U - series & $65,80,100,120,140$ & 6000 \\
\hline DIN 1026-2 & Hot rolled U-beam, UPE - series & $80,100,120,140,160$ & 6000 \\
\hline EN 10055 & Hot rolled T-beam, T - series & $50,60,70,80,100$ & 6000 \\
\hline EN 10210 & Seamless pipe & $60,70,88,95,108$ & 6000 \\
\hline EN 10219 & Seamless jäkl & $70,80,90,100,120$ & 6000 \\
\hline EN 10056 & Hot rolled L-shaped cross-section & $60,80,90,100,120$ & 6000 \\
\hline
\end{tabular}

\section{Results}

The FEM was used in this article to calculate the strength of the truss structure. This method is used to identify the distribution of forces and quantify the size of forces in the structure. The above-mentioned genetic algorithm has been chosen for optimization - to search through the design space for possible solutions. One-dimensional weight optimization was chosen as the first example, with a population of 250, 2500 and
25000 individuals in a generation. As can be seen in the Fig. 3 when 250 individuals were used for the calculation, the minimum weight of the structure was 544 $\mathrm{kg}$. There has been a reduction in convergence rates between the 30th and 40th generation, due to a relatively small population. When 2500 individuals were used in the calculation, the minimum weight of the structure was $526 \mathrm{~kg}$ and the convergence rate was reduced after approximately 20 generations. The results 
achieved with population of 25000 individuals are the best. The resulting construction weighs $521 \mathrm{~kg}$ and the results have not improved since the 80th generation.

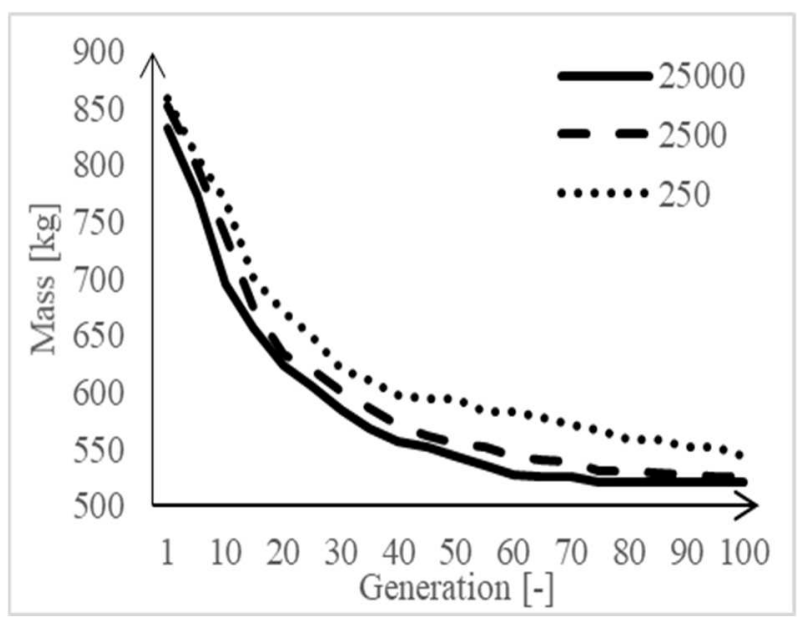

Fig. 3 Graph showing the progress of the best fitness value for each population during weight optimization

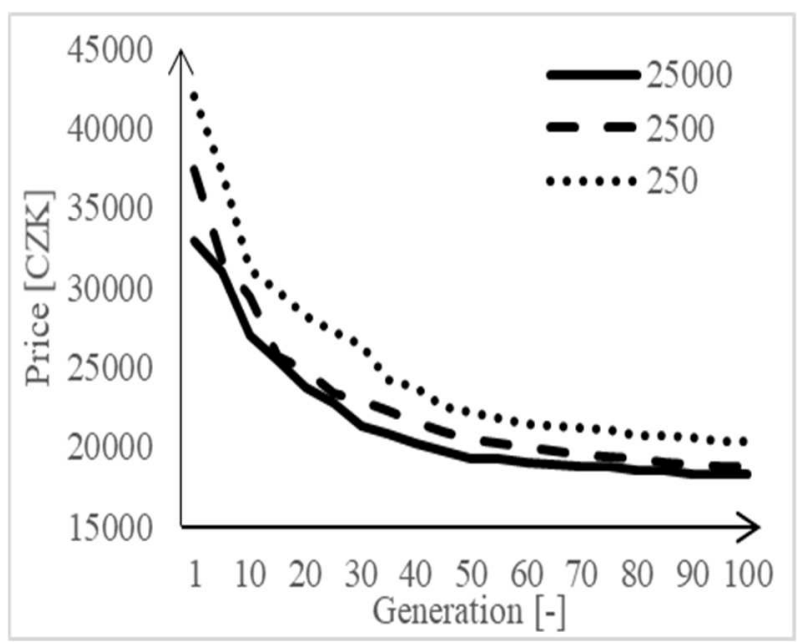

Fig. 4 Graph showing the progress of the best fitness value for each population during price optimization

In the second example, the goal was to find the minimal price of construction - including the minimum order length of individual profiles. Using the algorithm with 250 individuals per generation, a design with the minimum price of 20406 CZK was found. In this case the convergence rate reduced in two steps, the first occurred in the 10th generation and the second in the 35th generation. Using 2500 individuals per generation, the convergence rate reduced in the 15th generation and the minimum price for this structure was 18738 CZK. When 25000 individuals per generation were used, the convergence rate gradually decreased and results did not improve since the 90th generation. A minimum price of 18257 CZK was found for this variant, as seen in Fig. 4.

The 25-bars reference truss construction was chosen to verify the calculation of the algorithm. The model and simulations were performed in a classic
FEM program. NX was selected as a modelling program. MSC APEX software was used to prepare the FEM and calculate the forces, see Fig. 5.

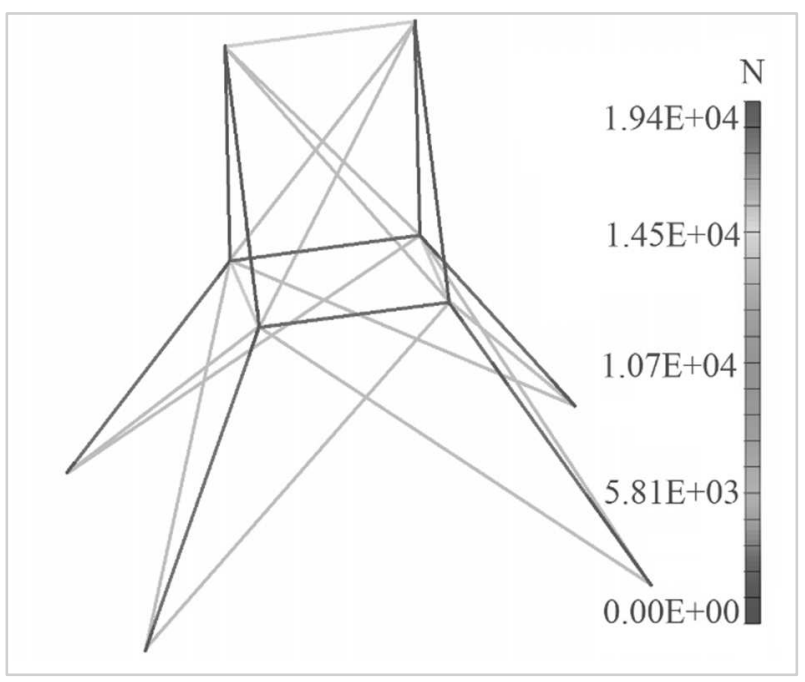

Fig. 5 Forces analysis of truss structure, distribution of forces in bars, maximum force is $19.4 \mathrm{kN}$

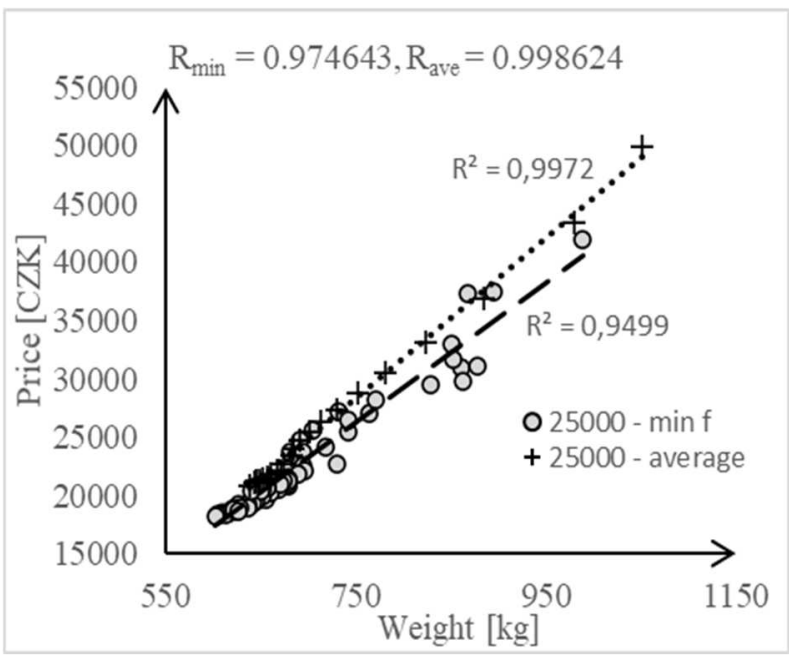

Fig. 6 Graph of correlation between the price and the weight of the structure, 25000 - min f are the best individuals in the population for each generation, 25000 - average are the average value of all feasible individuals in the population for individual generations

In the logical context of the second example, the data were analysed for the correlation between the price and the weight of the structure. It was found that the price optimization of the structure reduce its weight with the Pearson correlation coefficients $R_{\min }$ $=0.974643, R_{\text {ave }}=0.998624$. Two analyses were performed for the largest population - 25000 individuals in the population - and price optimization. In the first case, it is the average price and weight of feasible individual solutions for each generation. In the second case, it is taken to be the individual who has achieved the best value of fitness function in each generation. See Table 3 for detailed data. 
Tab. 3 Table of resulting data with calculation times.

\begin{tabular}{|l|l|l|l|l|l|}
\hline $\begin{array}{l}\text { Type optimi- } \\
\text { zation }\end{array}$ & $\begin{array}{l}\text { Size popula- } \\
\text { tion [-] }\end{array}$ & $\begin{array}{l}\text { Elapsed genera- } \\
\text { tion [-] }\end{array}$ & $\begin{array}{l}\text { Elapsed time } \\
{[\mathrm{s}]}\end{array}$ & $\begin{array}{l}\text { Best value } \\
{[\mathrm{kg} / \mathrm{CZK}]}\end{array}$ & $\begin{array}{l}\text { Num. generation } \\
\text { of best value [-] }\end{array}$ \\
\hline Weight & 250 & 100 & 1567 & 544 & 98 \\
\hline Weight & 2500 & 100 & 15633 & 526 & 94 \\
\hline Weight & 25000 & 100 & 148364 & 521 & 75 \\
\hline Price & 250 & 100 & 1499 & 20406 & 91 \\
\hline Price & 2500 & 100 & 15637 & 18738 & 98 \\
\hline Price & 25000 & 100 & 149695 & 18257 & 95 \\
\hline
\end{tabular}

\section{Conclusions}

Structural optimization is the main direction in which the development of new truss structures develops these days. This article outlines the possibility of solving mass optimization or price optimization. An important aspect in solving these problems was the inclusion of standards in the strength calculation, as well as buckling stability. Another very important point for calculating price during its optimization was the inclusion of the minimum order length of beams of the profile. In both cases, the best results were obtained using the largest population of 25000 individuals. At the end of the article, the hypothesis was stated that the use of price optimization can also lead to mass optimization of the structure, especially when all beams are made from the same material.

\section{Acknowledgement}

\section{The authors gratefully acknowledge funding from the Specific research on BUT FSI-S-20-6267.}

\section{References}

[1] BALUJA, S., CARUANA, R. (1995). Removing the Genetics from the Standard Genetic Algorithm. In: Machine Learning Proceedings 1995 (Morgan Kaufmann), pp 38-46. ISBN 9781558603776.

[2] DASGUPTA, S., GOSWAMI, A., RAO, B.V. (1993). On a Characterization of Uniform Distributions. Journal of Multivariate Analysis., Vol. 44(1), pp. 102-114. DOI: 10.1006/jmva.1993.1006. ISSN 0047259X.

[3] DAVID, E. G., DEB, K. A. (1991). Comparative Analysis of Selection Schemes Used in Genetic Algorithms. In: Foundations of Genetic Algorithms, Vol. 1, pp 69-93. Elsevier. ISSN 10816593. ISBN 9780080506845.

[4] HANZL, Pavel, Ivana ZETKOVÁ a Miroslav ZETEK. Specially Designed Lattice Structure for Milling Cutter Supported by FEA. Manufacturing Technology. 2019, 19(4), 579-582. DOI: 10.21062/ujep/337.2019/a/1213-

2489/MT/19/4/579. ISSN 12132489. Dostupné také z: https://arl.ujep.cz/arlujep/cs/detail-ujep_us_cat-0275286-Speciallydesigned-lattice-structure-for-milling-cuttersupported-by-FEA/

[5] HOLLAND, J. H. (1975). Adaptation in natural and artificial systems: An introductory analysis with applications to biology, control, and artificial intelligence, University of Michigan Press, 1975, ISBN 978-0-472-08460-9.

[6] KORA, P., YADLAPALLI, P. (2017). Crossover Operators in Genetic Algorithms: A Review. In: International Journal of Computer Applications, Vol. 162, pp 34-36. 10.5120/ijca2017913370.

[7] KAŠPÁREK, J., JONÁK, M., ŠKOPÁN, M. (2017). Design of the tracked chassis module. In Transport Means - Proceedings of the International Conference, (Kaunas University of Technology), pp. 666-670.

[8] KUČERA, P.; PÍŠTĚK, V. (2019). Prototyping a System for Truck Differential Lock Control. In: Sensors, vol. 19, no. 16, p. 1-18. ISSN: 1424-8220

[9] KUČERA, P.; PÍŠTĚK, V. (2017). Testing of the Mechatronic Robotic System of the Differential Lock Control on a Truck. In: International Journal of Advanced Robotic Systems, roč. 14, č. 5, s. 1-7. ISSN: 1729-8814.

[10] LI, Y., WANG, S., HAN, M. (2019). Truss Structure Optimization Based on Improved Chicken Swarm Optimization Algorithm. Advances in Civil Engineering. 2019, 1-16. DOI: 10.1155/2019/6902428. ISSN 1687-8086.

[11] MAŠEK, J.; BURGET, R.; KARÁSEK, J.; UHER, V.; GÜNEY, S. (2013). Evolutionary Improved Object Detector for Ultrasound Images. In 36th International Conference on Telecommunications and Signal processing. pp. 586590. ISBN: 978-1-4799-0402- 0. 
[12] MÜHLENBEIN, H., CHLIERKAMPVOOSEN, D. (1993). Predictive Models for the Breeder Genetic Algorithm I. Continuous Parameter Optimization. In: Evolutionary Computation, Vol. 1(1), pp 25-49. DOI: 10.1162/evco.1993.1.1.25. ISSN 1063-6560.

[13] TANG, K. S.; MAN, K. F.; KWONG, S.; HE, Q. (1996). Genetic Algorithms and their Applications. In: IEEE Signal Processing Magazine, pp. 22-37.

[14] SEGLA, Stefan, Jan KAMPO a Josef SOUKUP. Dynamic Analysis and Optimization of the Planar Model of the Trolleybus Škoda 21Tr. Manufacturing Technology. 2019, 19(3), 487-491. DOI: 10.21062/ujep/317.2019/a/1213-

2489/MT/19/3/487. ISSN 12132489. Dostupné také z: https://arl.ujep.cz/arlujep/cs/detail-ujep_us_cat-0273428-Dynamicanalysis-and-optimization-of-the-planar-model-of-the-trolleybus-skoda-21 $\mathrm{Tr}$ /
[15] SMITH, I. M., D. V. GRIFFITHS a Lee MARGETTS (2014). Programming the finite element method: with application to geomechanics., pp 5761., 4th edition. Chichester, UK: Wiley, 2014. ISBN 04-712-8003-8.

[16] WHITLEY, D. (1994). A genetic algorithm tutorial. In: Statistics and Computing. Vol. 4, Issue 2, pp 65-85. ISSN: 1573-1375.

[17] ZHANG, Wei, Liang HOU, Yawen GAN, Changhua XU, Xiangjian BU a Haojing LIN. Parallel Optimization of the Balancing and Sequencing for Mixed-model Assembly Lines. Manufacturing Technology. 2019, 19(3), 537-544. DOI: $\quad 10.21062 /$ ujep/325.2019/a/12132489/MT/19/3/537. ISSN 12132489. Dostupné také z: https://arl.ujep.cz/arlujep/cs/detail-ujep_us_cat-0273436-Paralleloptimization-of-the-balancing-and-sequencing-for-mixedmodel-assembly-lines / 